\title{
Variation and variability
}

$\mathrm{T}_{\mathrm{c}}^{\mathrm{h}}$

he world has been turned upside down with the novel Coronavirus pandemic. The most effective approaches to prevent the spread of the virus have been social distancing and wearing personal protective equipment (PPE), which has significantly changed our approach to life. Most of our daily activities have been altered, including medical appointments. My physicians have recommended that I cancel or postpone medical appointments that are not critical. To the extent that I am able, I have followed their advice.

My quarterly appointment with my ophthalmologist (for glaucoma) was reduced to tests of the intraocular pressure, which were conducted at a drive-thru location specially set aside in the parking lot at the facility. The nurse also used a small infrared thermometer to get a quick reading of my body temperature, which read $99.2^{\circ} \mathrm{F}$ instead of the normal temperature of $98.6^{\circ} \mathrm{F}$, which was slightly concerning.

I note that the PPE, the tool for measuring intraocular pressure, and the infrared temperature sensor are all results of materials research.

As materials researchers, we are all familiar with variation and variability. We know that even under the best of conditions, repeat measurements of the properties of materials vary in outcome. Wouldn't it be nice if every measurement was accurate with a precision only determined by the instrumentation? We could then make a single measurement on a single sample for each test condition and be absolutely sure of the result. There would never be any need to make another such measurement. Except, of course, for improvements in precision obtained as instrumentation advances.

Obviously, this is not the case. Material quality varies. Consider growth of semiconductor materials. We have a significant amount of experience growing some materials, such as silicon. Hundreds of thousands of wafers of silicon are processed every year by manufacturers of integrated circuits (ICs). ${ }^{1}$ And yet, IC manufacturers still encounter lot-to-lot variations in device performance, wafer-towafer variations within a lot, and device-to-device variations on a single wafer. Some of these problems are due to processing issues. Some are due to problems with materials. For those of us who perform research on semiconductor materials, we expect to obtain good results when we perform measurements on some materials (e.g., silicon, GaAs, germanium). However, other semiconductor materials (e.g., $\mathrm{HgCdTe}$ ) can be quite challenging. Although, the quality of $\mathrm{HgCdTe}$ samples has improved during the span of my career, working with it can still challenge the unwary. And now, we are attempting to develop materials based upon other ternary, quaternary, quinternary, and even larger agglomerations of materials.

As materials researchers, we know how to deal with variations in our measurements. ${ }^{2,3}$ We know that we need to characterize our samples properly before making measurements. We know that we should make measurements on multiple samples at each test condition and multiple measurements on each sample at each test condition. How many samples to measure and how many measurements to perform on each sample are determined by the quality of the samples and the resulting variability in the results. Measurements must then be characterized in terms of distributions, averages, and variances.

None of us would dream of reporting results without the appropriate statistical analysis that allows the reader to understand the significance of those results. Without error bars, we have no way of knowing whether trends in the data are significant or no way of determining whether models and simulations adequately fit the results.

As a materials researcher, I know and understand all of this. Why, then, should I be surprised to find that simple biological constructs, such as human body temperature, have variability, particularly considering the complexity of the human body?

The body temperature of $98.6^{\circ} \mathrm{F}$ was established by the German physician Carl Reinhold August Wunderlich in 1968. ${ }^{4}$ However, more recent studies place the normal range of human body temperature as $97.7-99.5^{\circ} \mathrm{F},{ }^{5}$ meaning my temperature was within the normal range.

Is this the whole story? Was I wrong to worry? The range of variation of human bodies is extraordinary. We have two different biological genders. We range from very short to very tall, from very thin to obese. Some of us are very fit, while others struggle to get out of our comfortable recliners. Our body mass index varies hugely. Human body temperature varies with health, gender, activity level, and age. It also varies by time of day and depends on how the measurement is made.

So what about me in this particular case? The temperature measurement was made around 2:00 pm, the handheld infrared thermometer had an accuracy of $\pm 0.5^{\circ} \mathrm{F}$, and I didn't develop any other symptoms, which argues that I was well.

More recent measurements of the distribution of human body temperatures indicate that average human body temperature has declined over the last century. ${ }^{6}$ This has been attributed to either a lessening of inflammation and the consequent lowering of body temperature or to a more sedentary lifestyle. Of course, the approaching zombification of the human race during the next pandemic will substantially reduce the average body temperature as well.

Steve Moss

\section{References}

1. www.semi.org/en/another-record-year-silicon-wafer-shipment-volumes-2015

2. R.L. Ott, M.T. Longnecker, An Introduction to Statistical Methods and Data Analysis, 7th ed. (Cengage Learning, Boston, 2015).

3. A. Gelman, J.B. Carlin, H.S. Stern, D.B. Dunson, A. Vehtari, D.B. Rubin, Bayesian Data Analysis, 3rd ed., Texts in Statistical Science Series, book 106 (Chapman \& Hall/CRC Press, Boca Raton, FL, 2013).

4. C.A. Wunderlich, Das Verhalten der Eigenwärme in Krankheiten (Verlag von Otto Wigand, Leipzig, Germany, 1868)

5. en.wikipedia.org/wiki/Human_body_temperature.

6. www.health.com/condition/cold-flu-sinus/normal-human-body-temperature.

This article was written in May 2020, after the Coronavirus began affecting the United States. 